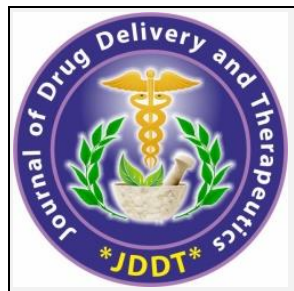

Open 2 Access
Available online on 15.11.2020 at http://jddtonline.info

\section{Journal of Drug Delivery and Therapeutics}

Open Access to Pharmaceutical and Medical Research

(C) 2011-18, publisher and licensee JDDT, This is an Open Access article which permits unrestricted non-commercial use, provided the original work is properly cited

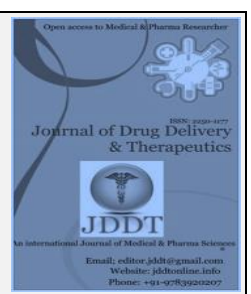

Research Article

\title{
Emerging Trends in the Burden of Cardiovascular Diseases in the Southeast Region of Nigeria
}

\author{
*Nkpozi Marcellinus 1, Adukwu Benjamin 2, Ezeude Chidiebele 3, Onwere Stephen 4 \\ ${ }^{1}$ Department of Internal Medicine, Abia State University Teaching Hospital, ABSUTH, Aba, Nigeria \\ 2 Department of Ophthalmology, Abia State University Teaching Hospital, ABSUTH, Aba, Nigeria \\ ${ }^{3}$ Department of Internal Medicine, Nnamdi Azikiwe University Awka/Nnamdi Azikiwe University Teaching Hospital, Nnewi, Nigeria \\ ${ }^{4}$ Department of Obstetrics and Gynaecology, Abia State University, Uturu, Nigeria
}

\begin{abstract}
Background and Objective: Cardiovascular diseases (CVDs) are leading causes of non-communicable diseases and are increasingly becoming the major causes of morbidity and mortality in Nigeria. Published literature on the changing patterns and outcome of CVD admissions in the southeast region of Nigeria is scanty. This study, therefore, set out to bridge this gap in knowledge.

Subjects and Methods: This was a 10-year retrospective descriptive study in which data about patients admitted on account of the CVDs to the medical wards of Abia State University Teaching Hospital (ABSUTH), Aba from May 1, 2007 to April 30, 2017 were extracted from the Admission/Discharge registers in the medical wards. Relevant data obtained were analyzed using Statistical Package for Social Sciences (SPSS) version 23.0 software.

Results: A total of 2044 patients were admitted because of CVDs, made up of 927 (45.4\%) males and 1117 (54.6\%) females. Cerebrovascular disease (stroke), heart failure (HF) and uncontrolled systemic hypertension (SHTN) were the major cardiovascular indications for hospitalization at $44.08 \%, 38.85 \%$ and $15.31 \%$ respectively. With an overall CVD mortality of $24.9 \%$ of the medical admissions, the commonest cause of CVD deaths was stroke. Majority of the CVD deaths (70.9\%) occurred within the first 7 days of hospitalization

Conclusion: Contribution of cardiovascular diseases to medical admissions is considerable in Aba, Southeast Nigeria. In-patient mortality of the CVDs is high especially from stroke. It is recommended that every effort should be made to control the modifiable risk factors of CVDs while early detection and treatment of CVDs be effected.
\end{abstract}

Keywords: Aba, cardiovascular diseases, medical wards, non-communicable diseases, Southeast, Nigeria

Article Info: Received 09 Sep 2020; $\quad$ Review Completed 19 Oct 2020; $\quad$ Accepted 26 Oct 2020; Available online 15 Nov 2020

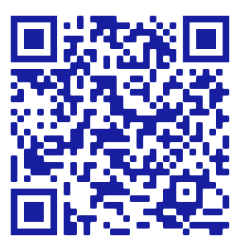

Cite this article as:

Nkpozi M, Adukwu B, Ezeude C, Onwere S, Emerging Trends in the Burden of Cardiovascular Diseases in the Southeast Region of Nigeria, Journal of Drug Delivery and Therapeutics. 2020; 10(6):18-23

http://dx.doi.org/10.22270/jddt.v10i6.4545

*Address for Correspondence:

Dr M.O. Nkpozi, Consultant Physician/Endocrinologist, Department of Internal Medicine, Abia State University Teaching Hospital, ABSUTH, Aba, Nigeria.

\section{INTRODUCTION}

Cardiovascular diseases are the commonest of the four major causes of NCDs which include cancers, chronic lung diseases and diabetes mellitus ${ }^{1,2}$. Nigeria and other SubSaharan African (SSA) countries are undergoing epidemiological transition ${ }^{3}$ arising from a decline in infectious diseases and a steady increase in NCDs as major causes of death. According to the WHO NCD country profile 2014, these low and middle income countries are, therefore, facing the double burden of communicable and noncommunicable diseases ${ }^{4}$. Etyang and Gerard Scott in their systematic review concluded that cardiovascular and infectious diseases were currently the leading causes of admissions and in-patient deaths in sub Saharan Africa5.

Non-communicable diseases accounted for an estimated $29 \%$ of all deaths in Nigeria with deaths due to CVDs, cancers, DM and chronic respiratory diseases being $11 \%$, $4 \%, 2 \%$ and $1 \%$ respectively ${ }^{6}$. Traditional risk factors of CVDs include hypertension, diabetes mellitus, dyslipidemia, obesity, smoking, family history of premature heart disease, microalbuminuria or glomerular filtration rate < $60 \mathrm{mls} /$ minute and sedentary lifestyle7. Newer risk factors8 include ethnic origin, socioeconomic status, increased serum levels of homocysteine, C-Reactive Protein, fibirinogen, triglycerides, glycated haemoglobin, lipoprotein a, plasma 
myeloperoxidase and red cell glutathione peroxidase 1 . Increased CVD burden in the developing countries has been attributed to urbanization, lifestyle changes, ageing of the population, high prevalence of cardiovascular (CV) risk factors such as DM, obesity, dyslipidaemia, and systemic hypertension 9 .

The most frequent CVDs include coronary heart diseases, stroke, hypertensive heart diseases, systemic hypertension, arrhythmias and heart failure ${ }^{10}$. In South Africa, CVD is the second leading cause of death following HIV/AIDS, accounting for about $40 \%$ of deaths in adults ${ }^{11}$ while in recent hospital based studies in Nigeria, CVDs accounted for $20.46 \%$ and $32.1 \%$ of medical admissions in Enugu 12 Southeast and Ekiti 13 , Southwest, Nigeria respectively. In a hospital based study in Keffi ${ }^{14}$, Northcentral Nigeria, CVDs were the predominant NCDs causing hospitalization followed by diabetes mellitus (DM) related complications at $37.7 \%$ and $23.7 \%$ respectively. In another hospital based study in South-western Nigeria15, CVDs accounted for $37.0 \%$ of all medical admissions with an overall mortality of $17 \%$ while in a hospital based study in Southwest Cameroun ${ }^{16}$, CVDs accounted for $15.9 \%$ of medical admissions with $15.8 \%$ in-hospital case fatality. In a Pakistan ${ }^{17}$ cross sectional study, the pattern of NCDs noted were systemic hypertension, ischemic heart diseases and DM at 38.7\%, $34.4 \%$ and $14.6 \%$ respectively with identified risk factors being tobacco use (48.2\%), drug abuse (13.6\%) and alcohol consumption (1.8\%). In Sheba Medical Centre, Israel, CVDs accounted for $41.2 \%$ of all medical admissions with systemic hypertension and ischemic heart disease being the predominant CVD indications for hospitalization ${ }^{18}$ while in Atbara teaching hospital, Sudan, CVDs were the predominant diagnoses at $16.4 \%$ of the NCDs in a country where NCDs accounted for $71.8 \%$ of all medical admissions ${ }^{19}$.

Cardiovascular diseases are the number one cause of death worldwide and more people die annually from CVDs than from any other disease 20 . Similarly, more than three quarters of CVD deaths take place in low and middle income countries $^{20}$. In the US, heart diseases are the leading cause of death for men, women and most people of the different racial groups with coronary heart disease being the commonest type of heart disease causing deaths ${ }^{21,} 22$ while CVDs accounted for $45 \%$ of all deaths in Europe and $37 \%$ of all deaths in the European Union ${ }^{23}$. Mensah et al24 noted that in SSA, the magnitude and trends in CVD deaths is incompletely understood but Susan Hamid et al ${ }^{25}$ reported an increasing prevalence of CVDs in the following selected SSA countries - Nigeria, Ghana, South Africa, Sudan and Tanzania.

Several Nigerian hospital based studies on CVDs are documented $13,14,18,26-28$, In Abia state, Southeast Nigeria, published literature on the changing patterns of CVD burden is scanty. This study, therefore, is aimed at bridging this gap in knowledge by determining the admission patterns and treatment outcome of CVDs in the medical wards of the only teaching hospital in the commercial city of Aba, Southeast, Nigeria. Data generated from this study will be useful to clinicians, policy makers, government and managers of health institutions to guide practice and appropriate healthcare budgeting leading to appropriate allocation of healthcare resources and services.

\section{SUBJECTS AND METHODS}

\section{Study design and Setting}

This was a retrospective descriptive study carried out on medical records of adult patients aged 18 years and above admitted on account of CVDs into the male and female medical wards of ABSUTH, Aba. Aba is a commercial city in the Southeastern region of Nigeria known for her industrial, mercantile and craftwork activities. The hospital is the only tertiary health facility in Aba and gets referrals from all the primary and secondary health facilities in Aba and the neighboring states. The medical wards (male and female) have 60 beds all together with 2 isolation wards. Medical inpatients come from the emergency department, medical outpatients clinic, Anti-retroviral Therapy (ART) clinic, transfers from the other specialties of the hospital such as the obstetrics/gynaecology or surgical wards. The Department of Internal Medicine, ABSUTH, Aba has Consultants in seven subspecialties with complement resident doctors and house officers. The medical wards have other support units such as the nursing unit, medical records, pharmacy section and the cleaners.

\section{Inclusion criteria}

All patients aged 18 years and above admitted on account of a CVD at the male and female medical wards were included in the study. Patients with repeat visits for different cardiovascular diagnoses within the study period were counted as two or more depending on their number of visits.

\section{Exclusion criteria}

Patients aged 18 years and above who were transferred from the surgical, gynaecologic or obstetric wards to the medical wards post-operatively because of a CVD complication arising after surgeries were not recruited for the study. This was to avoid confusions with determining their durations of hospital stay. Again, subjects with incomplete and missing data were excluded.

\section{Subjects Recruitment and Data Collection}

From May 1, 2007 to April 30, 2017, 2044 patients that met the inclusion criteria for the study were recruited. A total of 83 patients with diagnoses of CVDs had incomplete or missing data and were excluded from the study. Data for the study was extracted from patients' case notes, medical wards' Admission/Discharge registers and Death certificates and they included total number of medical admissions, demographic characteristics of subjects admitted for CVDs and treatment outcome at the medical wards. Data collected from each patient's record included - age, gender, definitive diagnosis, duration of hospital stay and outcome during admission. In this study, the outcome measures were improved and discharged home, died, discharged against medical advice (DAMA) or transferred to another specialty outside the medical wards or to another health facility.

\section{Ethical consideration}

Ethical approval was obtained from our Institution's Health Research Ethics Committee before commencing the study.

\section{Statistical Analysis of Data}

The Statistical Package for Social Sciences (SPSS Inc. Chicago IL. USA) version 23.0 statistical software was used for data analysis. For continuous variables such as the ages of the study subjects, mean values and standard deviations (SD) were calculated and the means compared using independent two samples t-test. Median duration of hospital stay and interquartile range was calculated because of the skewness of the data. Categorical variables such as the frequency of the diagnosis, sex and outcome of medical ward treatment were summarized using proportions expressed in percentages. The categorical variables were compared using the nonparametric test, chi square test. The level of statistical significance was set at $\mathrm{p}<0.05$. 


\section{RESULTS}

A total of 6587 medical admissions were recorded within the study period; 2044 (31.03\%) were patients admitted because of CVDs, made up of 927 (45.4\%) males and 1117 (54.6\%) females with a ratio of 1: 1.20. Cardiovascular diseases accounted for $42.7 \%$ of the NCDs in this study while the age range of the subjects was $18-103$ years with a mean age of $61.40 \pm 14.74$ years. Mean age of the males was 62.80 \pm 14.03 years and females $60.50 \pm 14.97$ years. The difference in the mean ages of the male and female patients was statistically significant $(t=3.47, p=0.001)$. Duration of hospital stay was 1 - 123 days with a median duration and interquartile range of 8 and 9 days respectively. The demographic characteristics of the study subjects were as summarized in Table 1.

More than half of the CVD admissions (58.3\%) were the elderly population (60 years and above) while the middle aged group (40-59 years) came second at 34.9\% (details in Table 2), the differences in outcome of the age groups is statistically significant $\left(\mathrm{X}^{2}=31.381, \mathrm{p}=0.002\right)$

Table 1: Demographic characteristics of patients that presented with CVDs in the medical wards of ABSUTH, Aba

\begin{tabular}{ll}
\hline Indices & Frequency $(\mathrm{n}=2044)(\%)$ \\
\hline Gender: & $927(45.4)$ \\
Male & $1117(54.6)$ \\
Female & \\
\hline
\end{tabular}

Age distribution of the subjects

$\begin{array}{ll}\text { Mean age }( \pm S D) & 61.53 \pm 14.60 \\ \text { Mean age male }( \pm S D) & 62.80 \pm 14.03 \\ \text { Mean age female }( \pm S D) & 60.50 . \pm 14.97 \quad(t=3.47, p=0.001)\end{array}$

Table 2: Gender and pattern of CVD indications for hospitalizations stratified by age groups in the medical wards of ABSUTH, Aba

\begin{tabular}{lllllllll}
\hline AG(years) & Male & Female & Stroke & HF & SHTN & CAD/IHD & SCA & Total(n=2044)(\%) \\
\hline$<20$ & 5 & 3 & 0 & 6 & 2 & 0 & 0 & $8(0.4)$ \\
$20-39$ & 39 & 101 & 32 & 69 & 30 & 8 & 2 & $140(6.8)$ \\
$40-59$ & 324 & 381 & 314 & 264 & 137 & 12 & 0 & $705(34.5)$ \\
$60-69$ & 236 & 284 & 262 & 195 & 78 & 4 & 0 & $520(25.5)$ \\
70 and above & 324 & 347 & 365 & 260 & 66 & 10 & 0 & $671(32.8)$ \\
Total & 927 & 1117 & 901 & 794 & 313 & 34 & 2 & $2044(100)$ \\
\hline
\end{tabular}

Key: $\mathrm{AG}=$ age groups, $\mathrm{HF}=$ heart failure, $\mathrm{SHTN}=$ uncontrolled systemic hypertension, CAD/IHD= coronary artery disease/ischemic heart disease, SCA= symptomatic cardiac arrhythmia.

\section{Pattern of CVD indications for hospitalization in ABSUTH, Aba.}

The predominant CVDs in this study were cerebrovascular disease (stroke), heart failure (HF) and uncontrolled systemic hypertension (SHTN) at 44.08\%, 38.85 and $15.31 \%$ respectively while coronary artery disease/ischemic heart disease (CAD/IHD) and symptomatic cardiac arrhythmia were low at $1.66 \%$ and $0.10 \%$ respectively. Details are in Table 3. Other CVDs such as peripheral artery diseases, deep vein thrombosis, pulmonary embolism and congenital heart diseases were not captured in our data source. The predominant CVDs in the study occurred more in the females than the males (Table 3 ) and more CVDs in women than men is statistically significant $\left(X^{2}=30.53, p=0.001\right)$

Table 3: Gender distribution of the CVD-indications for hospitalization in the medical wards of ABSUTH, Aba.

\begin{tabular}{lllc}
\hline Cardiovascular diseases & Male & Female & Total $(\mathrm{n}=2044)(\%))$ \\
\hline Cerebrovascular disease (stroke) & 429 & 472 & $901(44.08)$ \\
Heart failures & 372 & 422 & $794(38.85)$ \\
Systemic hypertension & 103 & 210 & $313(15.31)$ \\
CAD/ischemic heart disease & 23 & 12 & $34(1.66)$ \\
Cardiac arrhythmia & 0 & 2 & $2(0.10)$ \\
Total & 927 & 1117 & \\
\hline
\end{tabular}

Key: $\mathrm{CAD}=$ coronary artery disease

\section{Outcome of CVDs hospitalization in the medical wards of ABSUTH, Aba.}

A total of 1455 (71.2\%) of the CVD admissions into the medical wards improved and were discharged home, 509
(24.9\%) died, 69 (3.4\%) were discharged home against medical advice and $11(0.5 \%)$ were transferred to other centres or specialties. Of the CVD deaths, 154 (30.3\%) were middle aged subjects while $299(58.7 \%)$ were aged less than 70 years (Table 4 ).

Table 4: Outcome of CVD admissions stratified by age groups in ABSUTH, Aba..

\begin{tabular}{|c|c|c|c|c|c|}
\hline AG(years) & Improved & Died & DAMA & Referred & Total $(n=2044)(\%)$ \\
\hline$<20$ & 8 & 0 & 0 & 0 & $8(0.4)$ \\
\hline $20-39$ & 128 & 24 & 6 & 2 & $160(7.8)$ \\
\hline 40-59 & 511 & 154 & 28 & 5 & $698(34.1)$ \\
\hline $60-69$ & 386 & 121 & 24 & 3 & $534(26.1)$ \\
\hline $70 \&$ above & 422 & 210 & 11 & 1 & $644(31.5)$ \\
\hline Total & $1455(71.2 \%)$ & $509(24.9 \%)$ & $69(3.4 \%)$ & $11(0.5 \%)$ & $2044(100 \%)$ \\
\hline
\end{tabular}


With an overall CVD in-patient mortality of $24.9 \%$, the predominant causes of death within the study period were cerebrovascular disease (stroke) and heart failure at case fatality rates of $75.6 \%$ and $21.8 \%$ respectively. Majority of the subjects admitted because of uncontrolled systemic hypertension improved and were discharged home. Patients admitted on account of stroke were in majority in those who were discharged against medical advice (Table 5).

Table 5: Outcome of treatment of the CVDs in the medical wards of ABSUTH, Aba.

\begin{tabular}{lllllll}
\hline Outcome & Stroke & HF & HTN & IHD & C A & Total(n=2044)(\%) \\
\hline Home & 472 & 658 & 299 & 24 & 2 & $1455(71.2)$ \\
Died & 385 & 111 & 6 & 7 & 0 & $509(24.9)$ \\
DAMA & 38 & 20 & 8 & 3 & 0 & $69(3.4)$ \\
Transferred & 6 & 5 & 0 & 0 & 0 & $11(0.5)$ \\
Total & 901 & 794 & 313 & 34 & 2 & $2044(100)$ \\
\hline
\end{tabular}

Key: Home $=$ improved and discharged home, DAMA = discharged against medical advice, $\mathrm{HF}=$ heart failure IHD= ischemic heart disease, $\mathrm{HTN}=$ systemic hypertension $\mathrm{CA}=$ symptomatic cardiac arrhythmias

Majority of the CVD deaths (70.9\%) occurred within the first week of hospitalization with $24 \%$ of the deaths occurring within 24 hours of hospitalization. By the end of the second week, the death toll from CVDs had gone up to $84.1 \%$ of the CVD deaths. By day 30, majority of all those that survived $(93.9 \%)$ have been discharged home (Table 6).

Table 6: CVDs admission outcome on a day-by-day basis from day of hospitalization

\begin{tabular}{|c|c|c|c|c|}
\hline Day of admission & Home $(n=1455)$ & Died (n=509) & DAMA (n=69) & Referred(n=11) \\
\hline Day 1 & 11 & $122(\sim 24 \%)$ & $16(23.2 \%)$ & 2 \\
\hline Day 2 & 38 & 71 & 4 & 1 \\
\hline Day 3 & 80 & 69 & 8 & 1 \\
\hline Day 4 & 89 & 32 & 6 & 0 \\
\hline Day 5 & 90 & 22 & 4 & 2 \\
\hline Day 6 & 91 & 18 & 4 & 0 \\
\hline \multirow[t]{2}{*}{ Day 7} & 112 & 27 & 3 & 0 \\
\hline & Total $=511(35.1 \%)$ & Total=361(70.9\%) & Total $=45(65.2 \%)$ & Total $=6(54.5 \%)$ \\
\hline Day 8 & 150 & 13 & 3 & 3 \\
\hline Day 9 & 90 & 11 & 1 & 3 \\
\hline Day 10 & 87 & 13 & 1 & 2 \\
\hline Day 11 & 71 & $(10)$ & 3 & 0 \\
\hline Day 12 & 57 & 8 & 3 & 2 \\
\hline Day 13 & 72 & 9 & 1 & 7 \\
\hline \multirow[t]{2}{*}{ Day 14} & 56 & 2 & 2 & 4 \\
\hline & Total $=1094(75.2 \%)$ & Total=428(84.1\%) & Total $=59(85.5 \%)$ & \\
\hline Day 15 & 64 & 4 & 0 & 1 \\
\hline \multirow[t]{2}{*}{ to day 30} & 10 & 2 & 0 & 1 \\
\hline & Total=1366(93.9\%) & Total $=460(90.4 \%)$ & Total $=64(92.8 \%)$ & \\
\hline
\end{tabular}

\section{DISCUSSION}

The main findings of this study were that the CVDs contributed a predominant proportion of the medical admissions with cerebrovascular disease (stroke), heart failure and uncontrolled systemic hypertension being the commonest CVD indications for hospitalization. Stroke was the commonest cause of CVD deaths in the medical wards while an overall high CVD mortality was noted especially within the first week of hospitalization. .

Cardiovascular disease admissions accounted for $31.03 \%$ of all medical admissions within the study period and this is comparable to the $31.6 \%$ CVD admissions in a more recent study in Portharcourt 29 , Nigeria but higher than the $15 \%$, $18.8 \%$ and $20.1 \%$ reported respectively in Nnewi 26 , Enugu 12 and Umuahia ${ }^{18}$ (all in the Southeast Nigeria), $17.4 \%$ in Abeokuta $^{30}$, Southwest Nigeria, 19.9\% in Uyo ${ }^{31}$, Southsouth Nigeria and $14.1 \%-24.2 \%$ in Northern Nigeria ${ }^{32}$. However, in Keffi ${ }^{14}$, Northcentral Nigeria, CVDs accounted for a higher proportion of medical admissions at $37.7 \%$. Reason for

ISSN: 2250-1177 these disparities in the reports of these local Nigerian studies is not obvious but may be due to differences in the detection and control of the modifiable cardiovascular risk factors. This CVD in-hospital burden in the index study could, probably, be due to the epidemiologic transition from traditional scourge and burden of communicable diseases (CDs) to that of NCDs in Africa as reported by Omran ${ }^{9}$. It may, also, be in keeping with the WHO projection that by 2020, NCDs would surpass infectious diseases as the main cause of medical admissions and adult deaths ${ }^{33}$. Finally, it could be as a result of the westernized diets, sedentary lifestyles, resultant obesity and rapid urbanization observed to be taking place in the SSA countries including Nigeria.

Cardiovascular diseases were responsible for $42.7 \%$ of the NCD admissions in our study. This figure is lower than the $73.1 \%$ of NCD admissions noted in a Pakistan ${ }^{17}$ study but higher than the contribution of CVDs to NCD admissions in other Nigerian hospital based studies in Portharcourt27, Enugu $^{12}$ and Ido Ekiti ${ }^{34}$ where CVDs accounted for $35.7 \%$, 
$20.46 \%$ and $32.1 \%$ respectively. Explanations for the noted differences may be due to differences in the cardiovascular risk factors, economic activities, cultural and psychosocial factors prevalent in the different regions of Nigeria. It is noteworthy that, unlike what may be the case in Nigeria, tobacco use and drug abuse at $48.2 \%$ and $13.6 \%$ respectively were the predominant risk factors noted in the Pakistan ${ }^{17}$ study. This may, also, be the explanation for the higher CVDs frequency in the Pakistan study than in the index study. Cardiovascular diseases as a major cause of NCD admissions in this study corroborates the conclusion by Etyang and Gerard Scott in their systematic review that cardiovascular and infectious diseases were currently the leading causes of admissions and in-patient deaths in sub Saharan Africa ${ }^{5}$.

Many of the risk factors for cardiovascular diseases such as systemic hypertension, diabetes mellitus, hyperlipidemia/ dyslipidemia, sedentary lifestyles/physical inactivity, obesity, tobacco use and alcohol consumption are modifiable. The implication of this is that with proper health education, adequate healthcare financing, economic empowerment and effective national health insurance policy, the contribution of cardiovascular diseases to medical admissions can be reduced drastically. However, a worrisome situation is the reports in several studies that the cardiovascular risk factors are on the increase in Nigeria and other low income countries ${ }^{35-39}$. This underscores the importance of periodic evaluation of the patterns and outcome of CVD hospitalizations to guide practice and appropriate healthcare budgeting.

More females than males were hospitalized for CVDs within the study period. Similar observation was reported by Adedapo $^{15}$, Oguanobi et $\mathrm{al}^{40}$, Njoku et $\mathrm{al}^{14}$, Nwafor et $\mathrm{al}^{29}$ and Nkoke et al16 in Ibadan, Enugu, Keffi, Portharcourt and Southwest Cameroun respectively but contradicts those of some other researchers from within Nigeria 26,28 . This could be because the present study spanned over 10 years with more participants than the other studies which were for a period of 2-3 years with fewer study populations. It could, also, be due to a better health seeking behavior among females ${ }^{41}$ as reported by Omemu et al despite that it has been documented that males are at more risks than females for DM, strokes, chronic kidney diseases and other NCDs ${ }^{42}$.

The spectrum of CVDs that occurred most in the index study included strokes (44.08\%), HF (38.85\%) and uncontrolled SHTN $(15.31 \%)$ with CAD/IHD (1.66\%) playing a minor role. This is different from findings in majority of studies done in several centres in Nigeria as shown thus: Umuahia18, Southeast - SHTN 54.6\%, HF 36.8\%, Uyo ${ }^{31}$, Southsouth SHTN 55.7\%, HF 44.9\%, Abeokuta 30 , Southwest - SHTN $49.5 \%$, HF 44.9\%, Ile-Ife ${ }^{43}$, Southwest - SHTN 32\%, HF 35\%, and Keffi ${ }^{14}$, Northcentral - SHTN 71.2\%, HF 9.1\%, stroke $18.8 \%$. The commonest CVD indications for hospitalization in Sheba, Israel 18 was IHD and SHTN at $54.8 \%$ and $19.4 \%$ respectively which is comparable to reports from most other developed countries ${ }^{44}$. However, the index study is similar to a more recent study in Nnewi 26 , Nigeria where stroke, HF and SHTN contributed $46.7 \%, 30.9 \%$ and $20.9 \%$ respectively to medical admissions just as in the recent study in Portharcourt ${ }^{29}$, Nigeria where the situation was HF (43.1\%), stroke (24.3\%), uncontrolled SHTN (14.8\%) and acute myocardial infarction (1.6\%). This rising profile of stroke as a CVD indication for hospitalization is worrisome and calls for urgent measures to prevent these emerging patterns of CVDs in Nigeria and the low income countries. It is important to note that the noted patterns of CVD burden in the index study and the other Nigerian studies may be due to under-diagnosis or misdiagnosis of CVDs arising from non- utilization of echocardiography, computed tomography, doppler and duplex ultrasonography in the assessment of patients where indicated. Electrocardiography was the much available in most of those centres. This explains why CVDs like peripheral artery diseases, deep vein thrombosis, pulmonary embolism, vascular aneurysms and congenital heart diseases were not even captured in our data source.

Finally, in this study, $71.2 \%$ of the CVD admissions improved and were discharged home with a CVD mortality of $24.9 \%$. This is comparable to the $67.5 \%$ noted in Nnewi 26 , Southeast Nigeria but the CVD mortality was higher at $32 \%$ of the CVD admissions. In both studies, stroke had the highest case fatalities (44.08\% versus $65.3 \%$ ) of all the CVD indications for hospitalization. It is possible that in the setting of a dedicated stroke unit where multidisciplinary care services are rendered, the outcome would have been different from the current findings. In both studies, majority of the CVD deaths $(70.9 \%$ in our study versus $65.3 \%)$ occurred within the first week of hospitalization. This suggests probable serious shortcomings in intensive nursing and medical care which are crucial to a favorable outcome or could be due to late presentations to hospitals when patients conditions have deteriorated so much. The middle age population (4059 years) came second in the CVD admissions (34.1\%)) in our study and this is not good for the economic health of the nation as this age group is the main driver of the social and economic life of any nation. More than half of the CVD admissions (58.3\%) were aged 60 years and above; this is consistent with the overall trend of CVD which increases with increasing age ${ }^{45}$.

The limitations of this study include exclusion of some subjects on account of incomplete and missing data. Their inclusion may have altered the observed findings. This is an inherent limitation of retrospective studies. Another important limitation of the index study was the absence of postmortem examinations to corroborate the clinical diagnoses in most of the patients that died as a result of CVDs in the medical wards within the period under review.

\section{CONCLUSION/RECOMMENDATIONS}

This study has shown that the CVDs were the predominant diagnoses among NCD admissions in ABSUTH, Aba, Southeast Nigeria with cerebrovascular disease (stroke) being the commonest cause of cardiovascular deaths. Women and the elderly population were disproportionately affected. Dedicated stroke and geriatric units are recommended in ABSUTH, Aba and similar health facilities in Nigeria and sub-Saharan Africa. It is, also, recommended that prevention, early detection and effective management of $\mathrm{CV}$ risk factors be pursued to reduce morbidity and mortality from CVDs. Persons with CVDs or who are at increased CV risk need early detection and management using counseling and medications as appropriate

\section{CONFLICTS OF INTEREST: Nil}

\section{AUTHOR'S CONTRIBUTIONS:}

1. Dr Marcellinus O. Nkpozi - Conception and design of the research, drafting of the manuscript and taking care of the overall responsibility for the study.

2. Dr Benjamin O Adukwu - collection and analysis of the data.

3. Dr Chidiebere Ezeude - interpretation of the data and statistical analysis.

4. Prof. Stephen Onwere - Final approval and critical revision of the manuscript. 


\section{REFERENCES:}

1. World Health Organization. Global Health Observatory (GHO): deaths from NCDs. Available

from:https://www.who.int/en/news-om/factsheets/detail/noncommunicable-diseases

2. Kim HC, Oh SM. Noncommunicable diseases: Current status of major modifiable risk factors in Korea. J Prev Med Public Health 2013; 46:165-72

3. World Health Organization Non-communicable Diseases Country Profile 2014.

4. WHO. Global status report on non-communicable diseases: Geneva: World Health Organization; 2010. Available from: http://www.who.int/nmh/publications/ncd report 2010/en/[Last accessed on 2011 June 8].

5. Etyang AO, Gerard Scott GA, Medical causes of admissions to hospital among adults in Africa: a systematic review. Global Health Action, 2013; 10:3402/gha.v6i0.19090

6. Non-communicable diseases Country Profiles 2018. Geneva: World Health Organization; 2018. Licence: cc BY-NC-SA 3.0 IG0

7. Traditional Cardiovascular risk factors. Oxford Medicine https/oxford 10.1092/med/97800198784;906.001.0001.

8. Akhabue E, Thiboutot J, Chena JW, Vittona TJ, Christodoulides G, Grady KM et al. New and Emerging ris; $\mathrm{k}$ factors for coronary heart disease. Am J Med Sci 2014; 347(2):151-158.

9. Omran AR. The epidemiologic transition: A theory of the epidemiology of population change. Milbank Q. 2005; 83:731 757.

10. WHO Media Centre. Cardiovascular Diseases (CVDs), Fact Sheet No. 317. WHO Media Centre. WHO; January, 2011.

11. Peer N, Steyn K, Dennison CR, Levitt NS, Nyo MT, Nel JH, et al. Determinants of target organ damage in black hypertensive patients attending primary health care services in Cape Town: The Hi-Hi study. Am J Hypertens 2008; 21:896-902.

12. Ike SO. The pattern of admissions into the medical wards of the University of Nigeria Teaching hospital, Enugu; Niger J Clin Pract. 2008; 11(3):185-192

13. Ogunmola OJ, Oladosu OY. Pattern and outcome of admissions in the medical wards of a tertiary health center in a rural community of Ekiti state, Nigeria. Ann Afr Med 2014; 13:195203.

14. Njoku PO, Enomina M, Obehighe EE, Mbah IO, Okoro EO, Essen ME, Asalu AF, Kana UA. Pattern of non-communicable diseases seen in a tertiary hospital in Keffi, North Central Nigeria. Nig J Cardiol 2019; 16:60-65.

15. Adedapo AD. Rising trend of cardiovascular diseases among South-Western Nigerian female patients. Nig J Cardiol 2017; 14:71-74

16. Nkoke C, Jingi AM, Makoge C, Teuwafeu D, Nkouonlack C, Dzudie A, Epidemiology of cardiovascular diseases related admissions in a referral hospital in the South West region of Cameroon: A cross-sectional study in sub-Saharan Africa. PLoS ONE 2019; 14(12):e0226644. https://doi.org/10.1371/journal.pone.0226644

17. Naseem S,Khattak UK, Ghazanfar H, Irfan A. Prevention of NCDs and their risk factors at a semi-urban community, Pakistan. Pan $\begin{array}{lll}\text { African } & \text { Medical journal. 2016; 23:151 [doi }\end{array}$ 10.11604/pamj.2016.23.151.8974]

18. Ukpabi OJ, Uwanurochi K. Comparing indications for cardiovascular admissions into a Nigerian and an Israeli Hospital. Ann Afr Med 2017; 16:70-3

19. Noor SK, Elmadhoun WM, Bushara SO, Ahmed MH. The Changing Pattern of Hospital Admission to Medical Wards: Burden of non-communicable diseases at a hospital in a developing country. Sultan Qaboos Univ Med J. 2015; 15(4):e517-e522. doi:10.18295/squmj.2015.15.04.013.

20. WHO Key Fact Sheet 2017.

21. Heron M. Deaths: Leading causes for 2017. National Vital Statistics Reports; 2017; 68(6). Accessed November 19, 2019.

22. Benjamin EJ, Muntner P, Alonso A, Bittencourt MS, Callaway CW, Carson AP, et al. Heart disease and stroke statistics - 2019 update: a report from the American Heart Association. Circulation. 2019; 139(10):e56-528.

23. European Cardiovascular Disease Statistics 2017.

24. Mensah GA, Roth GA, Sampson UK, et al. Mortality from cardiovascular diseases in sub-Saharan Africa. 1990-2013: a systematic analysis of data from the Global Burden of Disease Study 2013. Cvja. 2015; 26:S6-S10.

25. Susan Hamid, Wim Groot and Milena Pavlova, Trends in cardiovascular diseases and associated risks in sub-Saharan Africa: a review of the evidence for Ghana, Nigeria, South Africa, Sudan and Tanzania. The Aging Male, 2019; 22(3):169-176, DOI:10.1080/13685538.2019.1582621.

26. Charles Ukachukwu Osuji et al. Pattern of cardiovascular admissions at Nnamdi Azikiwe University Teaching Hospital Nnewi, South East Nigeria. Pan African Medical Journal. 2014; 17:116. [doi: 10.11604 /pamj.2014.17.116.1837]

27. Unachukwu CN, Agomuoh DI, Alasia DD. Pattern of noncommunicable diseases among medical admissions in Portharcourt, Nigeria. Niger J Clin Pract. 2008; 11(1):14-17.

28. Ngwogu KO, Onwuchekwa UN, Ngwogu AC, Ekenjoku AJ. incidence, pattern and outcome of cardiovascular admissions at the Abia state university teaching hospital, Aba: A five year review. IJBAIR. 2015; 4 (3):54 - 61.

29. Nwafor CE, Alikor CA. Pattern of cardiovascular disease admissions in the medical wards of the University of Port Harcourt Teaching Hospital: a retrospective review. The Nigerian Health Journal. 2016; 16(2):42-9.

30. Ogah SO, Akinyemi RO, Adetutu A, Ogbodo EI. Analysis of medical admissions at the emergency unit of FMC, Abeokuta: A 2 year review. Afr J Biomed 2012; 15:59-63

31. Ansa VO, Ekott JU, Bassey EO. Profile and outcome of cardiovascular admissions at the university of Uyo teaching hospital, Uyo - A five year review. Niger J Clin Pract 2008; 11:22-24.

32. Mulcadus AO, Misbau U. Incidence and pattern of cardiovascular disease in North-west Nigeria. Niger Med J 2009; 50:55-57.

33. WHO. Global status report on non-communicable diseases: Geneva: World Health Organization; 2010. Available from: http://www.who.int/nmh/publications/ncd report 2010/en/[Last accessed on 2011 June 8].

34. Ogunmola OJ, Oladosu OY. Pattern and outcome of admissions in the medical wards of a tertiary health center in a rural community of Ekiti state, Nigeria. Ann Afr Med 2014; 13:195203.

35. Ejim EC, Okafor CI, Emehel A, Mbah AU, Onyia U, Egwuonwu $\mathrm{T}$, et al. Prevalence of cardiovascular risk factors in the middleaged and elderly population of a Nigerian rural community. J Trop Med 2011; 2011:308687.

36. Ike SO, Arodiwe EB, Onoka CA. Profile of cardiovascular risk factors among priests in a Nigerian rural community. Niger Med J 2007; 48:79-84.

37. Ulasi II, Ijoma CK, Onodugo OD. A community-based study of hypertension and cardio-metabolic syndrome in semi-urban and rural communities in Nigeria. BMC Health Serv Res 2010; 10:71-6.

38. Sani MU, Wahab KW, Yusuf BO, Gbadamosi M, Johnson OV, Gbadamosi A. Modifiable cardiovascular risk factors among apparently healthy adult Nigerian population - A cross sectional study. BMC Res Notes 2010; 20:3-11.

39. Lawoyin TO, Asuzu MC, Kaufman J, Rotimi C, Owoaje E, Johnson $\mathrm{L}$, et al. Prevalence of cardiovascular risk factors in an African, urban inner city community. West Afr J Med 2002; 21:208-11.

40. Oguanobi NI, Ejim EC, Onwubere BJC, Ike SO, Anisiuba BC, Ike VO et al. Pattern of cardiovascular disease amongst medical admissions in a regional teaching hospital in Southeastern Nigeria. Nig J Cardiol 2013; 10(2):77-80.

41. Omemu VO, Okogie OH, Omemu CEO. Awareness of high blood pressure status, treatment and control in a rural community in Edo state. Nig J Clinical Pract. 2007; 10:208-212.

42. Hawkes S, Buse K. Gender and global health: evidence, policy and inconvenient truths.. The Lancet. 2013; 381(9879):17831787.

43. Adedoyin RA, Adesoye A. Incidence and pattern of cardiovascular disease in a Nigerian teaching hospital. Trop Doct 2005; 35:104-106.

44. Mensah GA, Brown DW. An overview of cardiovascular disease burden in the United States. Health Aff 2007; 26:38-48.

45. Fleg JL, Aronow WS, Frishman WH. Cardiovascular drug therapy in the elderly: benefits and challenges. Nat Rev Cardiol. 2011 Jan; 8(1):13-28. pmid:20978470 